\title{
AS IMAGENS DE PORTUGAL NA POESIA DE CAMILO PESSANHA
}

\author{
Rodrigo Vasconcelos Machado \\ Universidade Federal de Minas Gerais
}

\begin{abstract}
É mais um povo que pelos séculos dos séculos terá de arrastar um destino próprio, a fazer milagres da pobreza do chão, das vogais da língua, do lirismo da alma. De vez em quando poderá ter um acesso de fúria e tentar fugir de si. Baldada ilusão. Aonde chegar será sempre ele ainda, a morrer de saudade e a sonhar o regresso da aventura com uma pequena reforma. Como bálsamo, restar-lhe-á o narcisismo e o somático contentamento de ver crescer e progredir os mundos que descobriu e civilizou. (...)

Miguel Torga, Portugal, 1996, p. 14.

(...) E o Penedo da Meditação, a Lapa dos Esteios, o Jardim Botânico e o Parque de Santa Cruz vivem perpetuamente num banho-maria nostálgico que, sendo uma realidade física local, é simultaneamente a atmosfera mental do português.
\end{abstract}

Idem, p. 87.

\section{A questão da imagem}

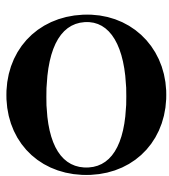

escritor português Miguel Torga evoca nas epígrafes anteriores uma temática fundamental para a compreensão da literatura portuguesa, que é o saudosismo pelo passado de glórias. Os descobrimentos, a reconquista cristã e outros marcos da história de Portugal estão representados no imaginário português por imagens que foram reformuladas por diversos escritores. Podemos inferir inicialmente que esta busca do tempo perdido, pela intelectualidade portuguesa, baseia-se na análise destas imagens a partir do seu contexto histórico-social. Para entender melhor este trabalho operado pelos intelectuais portugueses temos que considerar a imagem na sua acepção semiótica, isto é, como um 
texto-ocorrência suscetível de ser analisado. Segundo Greimas, a iconicidade da imagem é um efeito de conotação veridictória, relativa a uma determinada cultura, que julga certos signos mais reais que outros. ${ }^{1}$ A imagem possibilitaria, assim, uma relação dialógica entre o passado que a compõe e um presente que a conserva viva, e que consente a sua recorrência. Como assinala Alfredo Bosi, em seu livro intitulado O ser e o tempo da poesia: "a imagem pode ser retida e depois suscitada pela reminiscência ou pelo sonho. Com a retentiva começa a correr aquele processo de co-existência de tempos que marca a ação da memória: o agora refaz o passado e convive com ele." 2

No final do século XIX, a realidade material para os simbolistas era a sociedade em que viviam. Esta sociedade estava em franco processo de industrialização, principalmente França e Inglaterra, enquanto que Portugal se encontrava na "periferia" do capitalismo ocidental. O desenvolvimento tecno-científico do final do século XIX era enformado pelo ideário positivista e científico. Para os poetas simbolistas, esta sociedade não satisfazia os seus anseios; por conseguinte, a sua atitude era a de representar nas suas poesias o seu mundo interior, devido a desilusão com a sociedade industrializada e a angústia da falta de sentido da vida. Esses simbolistas adotavam a configuração platônica da visão de mundo que implicava a sobreposição da realidade material, sem importância para eles, e a realidade espiritual, eterna e completa. A linguagem seria o instrumento que permitiria aos simbolistas prefigurar, por meio de metáforas e símbolos, o seu "eu-profundo". O signo para os simbolistas adquiria um novo valor, na medida em que a capacidade adâmica de nomear as coisas, de apreender o irreal, o indizível, conferiria a eles o poder, segundo Heidegger, de "fundar o que permanece":

${ }^{1}$ GREIMAS, Dicionário de semiótica, p.226.

${ }^{2}$ BOSI, O ser e o tempo da poesia, p.13. 
El poeta nombra a los dioses y nombra a todas las cosas en lo que son. Ese nombrar no consiste en que algo ya conocido antes sea provisto sólo de un nombre, sino en que al decir el poeta la palabra esencial, mediante esa denominación, lo que es resulta nombrado como lo que es. Así es conocido como ente. Poesía es auténtica fundación del ser. Lo que permanece, nunca es, pues, creado a partir de lo transmitorio. Lo sencillo no se deja nunca captar inmediatamente a partir de lo enredado. La medida no reside en lo desmesurado. Nunca hallamos el fundamento en el abismo. Pero puesto que el ser y la esencia de las cosas nunca se pueden alcanzar y derivar a partir de lo existente, deben ser creados, establecidos y otorgados libremente. Tal libre donación es fundación. ${ }^{3}$

Desse modo, a fundação do que permanece seria realizada tanto pela imagem como pelo símbolo. A imagem seria a reconciliação entre o nome e o objeto, isto é, o seu sentido é ela mesma. A representação imagética pode ser uma pintura, uma fotografia - de objetos -, já o símbolo também pressuporia a homogeneidade entre o significado e o significante. A práxis poética, a partir da criação de imagens e símbolos pela linguagem, fundaria um tempo novo.

\section{A representação das imagens de Portugal na poética de Camilo Pessanha}

Na poesia de Camilo Pessanha (1867-1926), ${ }^{4}$ a evocação das imagens das glórias do século XVI e da consolidação do estado português aparecem como símbolos da época anterior e mostram

${ }^{3}$ HEIDEGGER, Arte y poesía, p. 61.

${ }^{4} \mathrm{O}$ seu único livro publicado em vida foi Clepsydra, por D. Ana de Castro Osório, em 1920. Há notícia também de outra publicação considerável de poemas de Camilo Pessanha na Revista Centauro, de 1916. Já edições posteriores apresentavam diversas versões dos poemas devido a escassez de autógrafos. Para este estudo, nos valeremos da primorosa edição crítica de Paulo Franchetti, de 1995, que corrigiu a maioria das impropriedades das anteriores. 
um lugar onde o país poderia buscar a sua força espiritual para reiniciar as navegações e sair da estagnação que se encontrava. O crítico José Seabra Pereira assinala que o desencanto com a sociedade fez com que os simbolistas se utilizassem dos seus mitos de uma nova maneira: "O uso que os simbolistas fazem do mito e da lenda distancia-se, aliás, do pitoresco evasivo pelo fato de aqueles serem considerados, na sua universalidade, como elementos poéticos fundamentais na realização de uma estética." Além de tratar de temas do ideário simbolista, Camilo Pessanha abordou em alguns dos seus poemas, sobretudo "San Gabriel" e "Quando?", matérias relativas ao passado mítico português. Pessanha seria uma das "antenas da raça", que conduziria o leme ${ }^{6}$ da nação portuguesa em direção às novas navegações, como ressalta Paulo Motta Oliveira:

Se no passado os portugueses saíram concretamente do velho continente em busca do caminho das Índias, processo que possibilitou à Europa toda a sua evolução posterior, agora que de novo o continente apresenta uma carência, desta feita de caráter espiritual, são de novo os portugueses que partem do porto seguro das certezas existentes, para o mar tempestuoso da criação desta nova sintese religiosa/civilizacional, como que refazendo e confirmando o papel pioneiro que tiveram no passado. E esta viagem está ocorrendo principalmente na poesia, e ela é ou a concretização ou o prenúncio desta metamorfose pela qual o país está passando, e cujo efeito remoto será uma Europa nova e reestruturada? (O grifo é meu)

5 PEREIRA, Decadentismo e simbolismo na poesia portuguesa, p. 86.

${ }^{6}$ Segundo Paulo Motta Oliveira, “(...) cabe aos poetas o comando, mesmo que temporário, da nação. Se são estes que, já em um estágio superior, estão recuperando as características esquecidas do país e realizando a síntese necessária para a cultura européia, são eles certamente que devem comandar a nação, e encabeçar a cruzada educativa, até que todo país tenha atingido este mesmo estágio." In: OLIVEIRA, Esperança e Decadência: as imagens de Portugal na $2^{a}$ série de A águia, p. 191.

${ }^{7}$ Idem, ibidem, p. 191. 
A poética de Camilo Pessanha foi um dos anúncios das mudanças pelas quais Portugal estava passando. Todavia, observando mais detidamente o livro Clepsydra, verificamos a presença do pessimismo que marcou o período de 1890 a 1910 em Portugal. O pessimismo português acompanhou os postulados de Schopenhauer e Hartmann, mas com especificidades próprias, que lhe deram um matiz distinto. Segundo Bernard Martocq, o pessimismo teria duas formas. A primeira seria filosófica e metafísica, sendo o resultado um produto da razão, que formaria um sistema coerente. Já a segunda seria psicológica e literária. O pessimismo português teve como principal influência a primeira. O principal interlocutor entre as idéias de Schopenhauer e Hartamann e o pessimismo português foi Antero de Quental, como nos assinala Bernard Martocq: “(...) assurément, les noms des deux porte-paroles officiels du pessimisme sont souvent cités à cette époque, mais il faut préciser qu'ils le sont d'autant plus qu'ils sont peu lus. Il ný a guère qu'Antero, la tête la plus philosophique de sa génération, qui ait eu une connaissance assez détaillée de ce probléme."

A questão do pessimismo em Portugal pode ser verificada na obra poética de Camilo Pessanha. O próprio nome Clepsydra provindo do grego klepsydra - e que passou a ser posteriormente clepsydra no latim - significa literalmente relógio de água, mas que metaforicamente alude à idéia de circularidade e/ou de fugacidade da vida do filósofo grego Heráclito de Éfeso: "Para as almas, morrer é transformar-se em água, para a água, morrer é transformar-se em terra. Da terra contudo, forma-se a água, e da água a alma." A esta proposição cíclica podemos contrapor a de Oliveira Martins que propugnava pelo retorno ao passado de glórias de Portugal, só que não seria um simples arremedo deste passado e sim, uma nova navegação no plano espiritual:

\footnotetext{
${ }^{8}$ In: MARTOCQ, Le pessimisme au Portugal, p. 422.

${ }^{9}$ HERÁCLITO DE ÉFESO, Fragmentos, p. 38.
} 
Nós acreditamos firme e diremos até piamente (...) na futura organização das nações da Europa; cremos portanto em uma vindoura Espanha mais nobre e mais ilustre do que foi a do século XVI. Acreditamos também que já hoje navegamos na viagem para este porto, embora os nevoeiros conturbem as vistas dos nautas agora que apenas acabamos de largar as costas do velho mundo. ${ }^{10}$

Contudo, entre os poemas de Camilo Pessanha e o pensamento de Oliveira Martins devemos guardar as devidas ressalvas, mormente no que se refere à questão das novas navegações que seriam realizadas no plano espiritual, como nos indica Paulo Motta Oliveira:

O que em Martins era uma analogia entre a missão passada e o destino futuro aqui (Paulo Oliveira se refere ao poema "San Gabriel") se converte em uma construção mais intricada: não apenas existe esta analogia entre os dois tempos, mas o passado não possui um significado em si, já que é apenas o início de algo que só em um futuro poderá se consumar. ${ }^{11}$

Esta luz no fim do túnel de novas navegações num plano espiritual foi a saída para a intelligentsia portuguesa do final do século XIX. A capitulação do governo português ao Ultimatum inglês de 1890 colocou em xeque a posição dos intelectuais da geração de 70, que comungavam das idéias desenvolvidas nas Conferências do Casino. Como exemplo disso temos Antero de Quental, que comandou a liga patriótica do norte e logo após se suicidou. É interessante observar, de acordo com José Seabra Pereira, que Antero de Quental propunha outra alternativa ao impasse em que Portugal estava mergulhado, desde depois de 1890. Esta alternativa foi proposta no seu testamento filosófico, as Tendências gerais da filosofia do século XIX, na medida em que ele: "inseria no idealismo subjetivista um novo dinamismo que visava o alcance do eu absoluto e se aproximava do espiritualismo pelo livre-arbítrio dirigido à santi-

${ }^{10}$ MARTINS, História da Civilização Ibérica, p.338.

${ }^{11}$ OLIVEIRA, Em naus que são construidas daquilo de que os sonhos são feitos: A poesia como um novo navegar, p.2. 
dade."12 Para Antônio Quadros, esta crise decorrente do Ultimatum inglês de 1890 já vinha se desenvolvendo desde muito tempo:

O caráter conflitual do nosso ser conosco vem de longe, mergulha as sua raízes no século XVI, mas agravou-se no século XIX, sobretudo com a intervenção intelectual da geração de 70, que tomou consciência de alguns aspectos cruciais da nossa problemática, mas que em vez de ignorar por completo a sua outra face, ao mostrar-se afinal incapaz de fazer a síntese entre tese e a antítese. ${ }^{13}$

Se para Antônio Quadros a crise do final do século XIX já vinha se desenvolvendo desde o século XVI, para Eduardo Lourenço o Ultimatum inglês de 1890 seria o "traumatismo-resumo" do século XIX português:

O Ultimatum não foi apenas uma peripécia particularmente escandalosa das contradições do imperialismo europeu, foi o traumatismo-resumo de um século de existência nacional traumatizada. (...) Podia imaginarse que confrontados com tão dura lição viéssemos a reconsiderar um estado de abatimento e um comportamento de fuga complementar dele. Passado o momento da aflição patriótica, percorrido até ao absurdo o labirinto sem saída da nossa impotência, voltamos à costumada e agora voluntária e irrealística pose de nos considerarmos, por provincianice incurável ou despeito infantil, uma espécie de nação idílica sem igual. ${ }^{14}$

A poesia de Camilo Pessanha estaria constituída pelos pressupostos da estética simbolista, que abordaria uma temática de âmbito mais universal, como as questões da fugacidade da vida e o desencanto com a sociedade industrializada. O simbolismo em Portugal além de tratar dos temas sobreditos, também teve as suas particularidades e no seu representante máximo as imagens do passado mítico português se fazem presentes, como veremos em alguns de seus poemas no próximo tópico.

12 PEREIRA, Decadentismo e simbolismo na poesia portuguesa, p.124.

${ }^{13}$ QUADROS, A idéia de Portugal na literatura portuguesa dos últimos 100 anos, p.21

${ }^{14}$ LOURENÇO, Psicanálise mítica do destino português, p.28 e 29. 


\section{As imagens de Portugal na poesia de Camilo Pessanha}

Eu vi a luz em um paiz perdido.

A minha alma é languida e inerme.

Oh! Quem podesse deslisar sem ruído!

No chão sumir-se, como faz um verme... ${ }^{15}$

No poema mencionado acima temos como leitmotiv o sentimento de nostalgia do eu-lírico por um país perdido. A "luz" que o poeta vê pode ser inicialmente considerada como se relacionada a uma possível esperança, devido à conotação do termo "luz" significar este sentimento. Todavia, observando os versos seguintes, nos deparamos com uma atitude de impotência do poeta, que tem a "alma languida" e sem defesas. Diante do seu nascimento em uma pátria exausta e a sua inação, o eu-lírico tem como única saída possível "deslisar sem ruído" e se comparar com um dos mais ínfimos dos seres: o verme. A partir do que foi dito anteriormente, podemos inferir que a temática central do poema sobredito aponta para o pessimismo. Outro poema que também traz em seu bojo o pessimismo, mas que volta a sua mirada para o passado mítico de Portugal, aludindo ao período da Reconquista Cristã, é "Quando?":

$$
\text { QUANDO? }
$$

Quando se erguerão as setteiras, Outra vez, do castello em ruina?

E haverá gritos e bandeiras

$\mathrm{Na}$ fria aragem matutina?

Se ouvirá a rebate,

- Sobre a planície abandonada?

E partiremos ao combate,

De cota, e elmo, e a longa espada?

Quando iremos, tristes e serios, Nas prolixas e vãs contendas, Lançando juras, improperios, Pelas divisas e legendas?

${ }^{15}$ PESSANHA, Clepsydra, p.75. 
E voltaremos, - os antigos,

Os purissimos lidadores, -

Quantos trabalhos e perigos!

Quasi mortos e vencedores?

E quando, ó Doce Infanta Real,

Nos sorrirrás do belveder?

Magra figura de vitral

Por quem nós fomos combater. ${ }^{16}$

A reconquista Cristã o período da história de Portugal em que o estado se consolidou, período que permitiu, logo em seguida a época gloriosa das navegações. A "cruzada” portuguesa teve as suas especificidades, porque o inimigo não estava na Terra Santa e sim no solo pátrio português. Além de enfrentar os mouros, Portugal tinha que, a todo custo, obliterar as pretensões de Castela ao trono português. Os guerreiros que se destacaram nas guerras para a consolidação de Portugal seriam evocados no final do século XIX e início do século XX como exemplos a serem seguidos. Assim, temos no poema mencionado a interrogação do eu-lírico que pergunta "Quando" retornarão os valores espirituais que permitiram as grandes vitórias de Portugal nos campos de Algarve e Aljubarrota. O "real", com que o eu-lírico lança o seu questionamento, é o estado atual de Portugal depois do Ultimatum inglês de 1890, que mergulhou o país num estado de uma atividade inútil, que logo depois se tornaria apatia e/ou luta contra a monarquia portuguesa. A nova religiosidade, que estava em gestação na poesia de Camilo Pessanha, buscou nos avatares do passado o caminho para uma nova esperança. Era do passado de conquistas que viria o som da "rebate" que lançaria Portugal em novas navegações, porque historicamente após a consolidação de suas fronteiras, Portugal canalizou o seu esforço para os empreendimentos marítimos. Retomando o poema, podemos verificar que a "saudade" do passado glorioso é marcada pelos símbolos que caracterizam a

${ }^{16}$ Idem, ibidem, p. 94-95. 
época da Reconquista Cristã, como a "cota", o "elmo" e principalmente a "longa espada". Além destes instrumentos míticos, há alusão também aos "purissimos lidadores", entre os quais se destacam o condestável Nuno Álvares Pereira, que foi o grande vencedor da batalha de Aljubarrota; o rei D. Afonso Henriques, que reconquistou o Castelo de Óbidos em 1148 com ajuda do "lidador" capitão Gonçalo Mendes Maia; e muitos outros "guerreiros" que contribuíram para a derrota dos inimigos de Portugal. Na última estrofe de "Quando?" surge a presença da "Doce Infanta Real", que inspirou os guerreiros em seus combates e perigos, e que talvez pudesse ser D. Inês de Castro ou a Rainha Isabel. Podemos colocar que estes guerreiros realizam no plano terrestre o que mais tarde foi feito nos mares pelos nautas portugueses. Temos no poema "San Gabriel"17 a realização dessa nova navegação:

SAN GABRIEL

(No quarto centenario do descobrimento da India)

I

Inútil Calmaria. Já colheram

As vellas. As bandeiras socegaram,

Que tão altas nos topes tremularam,

- Gaivotas que a voar desfalleceram.

Param de remar! Emmudeceram!

(Velhos rithmos que as ondas embalaram)

Que cilada que os ventos nos armaram!

A que foi que tão longe nos trouxeram?

San Gabriel, archanjo tutelar,

Vem outra vez abençoar o mar,

Vem-nos guiar sobre a planicie azul

${ }^{17}$ A presente leitura do poema supracitado terá como apoio a análise de Paulo Franchetti e Maria Helena Nery Garcez no seu ensaio A viagem de vasco da Gama na virada do século e de outras leituras que serão citadas no decorrer do estudo. 
Vem-nos levar á conquista final

Da luz, do Bem, doce clarão irreal.

Olhae! Parece o Cruzeiro do sul!

II

Vem conduzir as naus, as caravellas, Outra vez, pela noite, na ardentia, Avivada das quilhas. Dir-se-ia

Irmos arando em um montão de estrellas.

Outra vez vamos! Concavas as vellas, Cuja brancura, rutila de dia, luar dulcifica, Feeria

Do luar não mais deixes de envolvel-as!

San Gabriel, vem-nos guiar á nebulosa

Que do horisonte vapora, luminosa

$\mathrm{E}$ a noite lactescendo, onde, quietas,

Fulgem as velhas almas namoradas...

-Almas tristes, severas, resignadas,

De guerreiros, de santos, de poetas. ${ }^{18}$

A temática dominante no poema acima é a esperança, em forma de prece dirigida ao arcanjo San Gabriel, o que nos remete tanto para o arcanjo da anunciação à Virgem Maria, como para o nome de uma das naus de Vasco da Gama (Cf. Franchetti, 52). A publicação do poema se deu em 7 de maio de 1898 em Macau, no "Jornal Único", celebrando os quatrocentos anos da viagem do Gama e aludindo à situação em que se encontrava Portugal depois de 1890. Assim, temos na primeira estrofe do díptico uma sucinta descrição da condição presente, que é assinalada pela "calmaria" que impede o movimento dos barcos. As "gaivotas" portuguesas que conquista-ram muitas glórias no passado apenas sofreram uma interrupção temporária que é suscetível de ser retomada. A partícula "nós" é que vai apontar para um ideal no plano coletivo (Cf. Franchetti, 56), isto é, o eu-lírico através da segunda pessoa do plural

${ }^{18}$ Idem, ibidem, p.94-95. 
coloca num âmbito coletivo toda a nação portuguesa, e através de uma analogia com o passado, propõe que este seja o início de algo que só em um futuro poderia se consumar. Para atingir isso, é solicitado o concurso da intervenção de uma entidade divina, o arcanjo San Gabriel, para novamente guiar os portugueses na nova navegação espiritual, pois eles podem outra vez se regenerar numa nova conquista espiritual, que é diferente de um simples retorno ao antigo poderio do século XVI. Enquanto a prece está sendo realizada, há esperança. A visão que Camilo Pessanha propõe nesta nova viagem não é, portanto, pessimista nem passadista. Portugal iria em direção a um novo empreendimento que todavia ainda não se completou e anunciaria o movimento saudosista, como corrobora Paulo Motta Oliveira:

Assim, neste poema ("San Gabriel") já estamos próximos das concepções que depois serão formuladas pelos saudosistas, seja pelo caráter espiritual e mesmo religioso que a navegação possui nestes sonetos, seja pela transformação da voz poética não só num profeta, mas também como um propiciador da nova benção do mar, que ele pede a San Gabriel. ${ }^{19}$

Na segunda parte do díptico, a prece dirigida ao arcanjo atinge os seus objetivos, pois na fosforescência marítima, as "quilhas" das naus brilham e renasce o movimento. Agora as velas dos barcos estão "concavas" e a luz que simboliza a esperança está presente por toda parte, como por exemplo nas próprias velas que são embaladas pela magia do luar "dulcificador". A partir daí, o sonho de novas navegações espirituais se torna "presentificado". A sufixação do termo lácteo em "lactescendo" pelo eu-lírico nos indica que o embranquecimento da "noite" em que Portugal se encontrava sinaliza para uma saída da estagnação. O sentido de purificação confere ao termo luz e aos demais do mesmo campo de significação, que Portugal vai ao encontro às antigas qualidades de sua alma

${ }^{19}$ OLIVEIRA, Esperança e Decadência: as imagens de Portugal na $2^{a}$ série de A águia, p. 202. 
nacional, como nos aponta Paulo Franchetti: "Da mesma forma, o aportar na luminosa deixa-se ler como a recuperação das antigas qualidades da alma nacional, de que a viagem do Gama é a realização mais emblemática." ${ }^{20}$

\section{Conclusão}

Podemos inferir pela análise dos três poemas de Camilo Pessanha, empreendida anteriormente, que as imagens de Portugal variam inicialmente de um pessimismo do sujeito da enunciação, por ter nascido num país onde a luz não significava esperança, para, em seguida, no poema "Quando?", à uma interrogação às ruínas do que ficou como monumento daquele passado glorioso. Este poema aponta para uma saída do pessimismo pelo uso de apetrechos que confeririam uma força, digamos, espiritual, devido à sua ligação com a época da Reconquista Cristã, aspecto que foi retomado por Fernando Pessoa no seu Mensagem:

IV. A COROA

NUNALVARES PEREIRA

Que aureola te cerca?

É a espada que, volteando,

Faz que o ar alto perca

Seu azul negro e brando.

Mas que espada é que, erguida,

Faz esse halo no céu?

É Excalibur, a ungida,

Que o Rei Arthur te deu.

Sperança consumada,

Portugal em ser,

Ergue a luz da tua espada

Para a estrada se ver!

${ }^{20}$ FRANCHETTI, A viagem de Vasco da Gama na virada do século, p. 56. 
No poema "Quando?" podemos observar que é uma "longa espada" que será usada para retomar as antigas qualidades dos heróis do passado, entre os quais se destaca a figura do condestável Nuno Álvares Pereira, que ao lado de D. Sebastião seria a conjugação do guerreiro e do santo. A diferença entre os dois seria que D. Sebastião perde a batalha de Alcacer Quibir e o seu corpo não é encontrado, tornando-se, assim, o "desejado" que restauraria o império português. Nuno Álvares Pereira é vitorioso, pois com sua inestimável ajuda, os portugueses vencem a batalha de Aljubarrota. Após isto, ele renuncia aos seus bens terrenos em prol de uma vida religiosa. No poema "A coroa", é a espada de Nuno Álvares Pereira que seria usada, como a mágica "Excalibur" pelo Rei Arthur, para que os portugueses revivessem a chama perdida da esperança e conquistassem novamente o seu lugar ao sol. No final de "San Gabriel", o eu-lírico evoca a presença destes grandes homens como uma integração entre a nação portuguesa atual e o seu passado no ser coletivo que seria o fim da viagem metáforica, mas como toda profecia, exige fé daquele que a profere, pois não se sabe como e quando se realizará. Podemos observar que em "A coroa" a necessidade da fé também está presente, uma vez que a presença de um novo destino está condicionada à "luz" da espada de Nuno Álvares Pereira, que descortinará, de acordo com Fernando Pessoa, uma nova estrada para o destino de Portugal:

Tenhamos fé. Tornemos essa crença, afinal, lógica, num futuro mais glorioso do que a imaginação o ousa conceber, a nossa alma e o nosso corpo, o quotidiano e o eterno nós. Dia e noite, em pensamento e ação, em sonho e vida, esteja conosco para que nenhuma das nossas almas falte à sua missão de hoje criar o supra-Portugal de amanhã. ${ }^{21}$

${ }^{21}$ PESSOA, A nova poesia portuguesa sociologicamente considerada, p.367. 


\section{Referências Bibliográficas}

BOSI, Alfredo. O ser e o tempo da poesia. São Paulo: Cultrix, 1997. CHEVALIER, Jean, GHEERBRANT, Alain. Dicionário de símbolos. Rio de Janeiro: José Olympio, 1995.

FRANCHETTI, Paulo, GARCEZ, Maria H. N. A viagem de Vasco da Gama na virada do século. Estudos Portugueses e Africanos, Campinas, n.22, p.51-64, jul.-dez. 1993.

GREIMAS, A. J., COURTÉS, J. Dicionário de semiótica. São Paulo: Cultrix, 1985.

HEIDEGGER, Martim. Arte y poesía. México: Fondo de Cultura, 1958. HERÁCLITO DE ÉFESO. Fragmentos. In: BORNHEIM, Gerad (org.). Os filósofos pré-socráticos. São Paulo: Cultrix, 1994.

LOURENÇO, Eduardo. Psicanálise mítica do destino português. $O$ labirinto da saudade. Lisboa: Dom Quixote, 1982.

MARTINS, Oliveira. História da civilização Ibérica. Lisboa: Guimarães Editores, 1973.

MARTOCQ, Bernard. Le pessimisme au Portugal (1890-1910). In: Arquivos do centro cultural português. v. 5. Paris: Fundação Calouste Gulbenkian, 1972.

MASSAUD, Moisés. Dicionário de termos literários. São Paulo: Cultrix, 1986.

OLIVEIRA, Paulo Motta. Esperança e Decadência: as imagens de Portugal na $2^{a}$ série de A águia. Campinas: Unicamp, 1995.

PAZ, Octavio. El arco y la lira. México: Fondo de Cultura, 1990.

PEREIRA, José C. Seabra. Decadentismo e simbolismo na poesia portuguesa. Coimbra: Instituto de Alta Cultura, 1975.

PESSANHA, Camilo. Ed. Crítica de Paulo Franchetti. Clepsydra. Lisboa: Relógio d'água, 1995.

PESSOA, Fernando. Mensagem. In: Obra poética. Rio de Janeiro: Nova Aguilar, 1995. p. 69/89.

. A nova poesia portuguesa sociologicamente considerada.

In: Obra em prosa. Rio de Janeiro: Nova Aguilar, 1995. 
QUADROS, Antônio. A idéia de Portugal na Literatura Portuguesa dos últimos 100 anos. Lisboa: Fundação Lusíada, 1989.

SARAIVA, José H. História concisa de Portugal. Lisboa: Publicações Europa-América, 1979.

SERRÃO, Joel. Esta palavra decadência. In: . Temas de cultura portuguesa. Lisboa: Livros Horizonte, 1983.

SIMÕES, João Gaspar. Perspectiva histórica da poesia portuguesa do século XX. Porto: Brasília Editora, 1976.

TELES, Gilberto Mendonça. Vanguarda européia e modernismo: apresentação dos principais poemas, manifestos, prefácios e conferências vanguardistas, de 1857 a 1972. Petrópolis: Vozes, 1994.

TORGA, Miguel. Portugal. Rio de Janeiro: Nova fronteira, 1996.

WILSON, Edmund. O castelo de Axel: estudo sobre a literatura imaginativa de 1870 a 1930. São Paulo: Cultrix, 1993.

\section{Resumo}

A questão que vamos trabalhar nesta investigação é a análise de algumas imagens de Portugal que aparecem na poesia de Camilo Pessanha. Antes, porém, de seguirmos com esta análise, apresentaremos algumas considerações sobre a imagem, para poder, em seguida, relacioná-la com o simbolismo e as ponderações de Oliveira Martins e Eduardo Lourenço. Ponderações estas que tratam das questões das "navegações" e do Ultimatum de 1890, respectivamente.

\section{Resumen}

La cuestión que vamos a trabajar en esta investigación es el análisis de algunas imágenes de Portugal que aparecen en la poesía de Camilo Pessanha. Antes de hacer este estudio, vamos a presentar algunas consideraciones sobre la imagem, para poder, en seguida, enlazarla con el simbolismo y los planteamientos de Oliveira Martins y Eduardo Lourenço. Ponderaciones estas que se refieren a las cuestiones de las "navegaciones" y del Ultimatum de 1890, respectivamente. 